\title{
Three Editions of Inter-University Studies on Space and Satellite Technology. Candidate and/vs. Graduate, a Case Study
}

\author{
Zbigniew Łubniewski, Przemysław Falkowski-Gilski, \\ Marek Chodnicki \\ Gdansk University of Technology \\ Narutowicza 11/12, 80-233 Gdańsk, Poland \\ lubniew@eti.pg.edu.pl
}

\author{
Andrzej Stepnowski \\ Polish Space Agency \\ Trzy Lipy 3, 80-172 Gdańsk, Poland
}

\begin{abstract}
Currently, there is a growing demand for most upto-date academic courses that will fulfil the needs of modern society. Each candidate has to make choices and judgements carefully, in order to succeed on the market. This is particularly important when educating individuals with different backgrounds, especially on an inter-university course in the field of space sciences and technology. This paper describes a case study carried out on a group of candidates and graduates from different editions of Space and Satellite Technologies interdisciplinary master studies at Gdansk University of Technology as well as two maritime universities in Gdynia. The education process itself is realized in cooperation with business partners. The paper provides both qualitative and quantitative data, considering the whole group and particular individuals. In addition, some examples of individual achievements of outstanding students are presented.
\end{abstract}

Keywords-Inter-University Studies on Space and Satellite Technology; candidates and graduates; university and business cooperation; career in space sector

\section{INTRODUCTION}

Three big universities in Tricity (the agglomeration of 3 cities: Gdańsk, Gdynia and Sopot in Northern Poland), namely, Gdańsk University of Technology (GUT), Gdynia Maritime University (GMU) and Polish Naval Academy in Gdynia (PNA), with co-operation with the Polish Space Agency in Gdańsk, started in 2017 the interdisciplinary, MSc degree studies on Space and Satellite Technologies (SST). Each of these universities offer for their candidates and conduct special education in case of certain specialty.

Faculty of Electronics, Telecommunications and Informatics GUT, recruits students for specialty: Information and telecommunications technologies in space and satellite engineering. Faculty of Mechanical Engineering GUT, recruits students for specialty: Mechanical and mechatronic technologies in space engineering. Faculty of Electronics Gdynia Maritime University, recruits students for specialty: Marine satellite and space systems. Faculty of Command and Naval Operations Polish Naval Academy in Gdynia, recruits students for specialty: Space and satellite applications in security systems.
This new initiative in the field of education in Polish Pomerania region is an answer to the development of the innovative industry sector of space exploration and utilization technologies. It is expressed by the increase of a number of companies and other entities related to space sector in Poland, also in Pomerania region. The new space sector entities are both the Polish branches of well recognized international corporations operating for a long time in space industry, and smaller local firms offering services in the areas including satellite telecommunications, satellite navigation, Earth observation and Geographic Information Systems.

\section{DESCRIPTION OF THE UNIVERSITY STUDIES}

The detailed curriculum of the SST studies has been presented in [1]. The curriculum of the studies combines the contents of basic courses, like mathematics, physics or astronomy, with advanced topics of satellite technology utilization (satellite telecommunications, remote sensing and navigation), space missions, space mechanisms and constructions, as well as space applications in security systems. The graduates of SST studies also obtain skills on using as well as designing of specialized space equipment. The students are also provided with basics of legal regulations with respect to space activities. The wide spectrum of topics covered by the SST studies curriculum results in obtaining by students the background in numerous fields related to space.

Within the scope of educational activities predicted for of SST students during their studies, the directly take part in scientific research projects, under the supervision and in cooperation with the academic and research staff. As a result, they are prepared to independent formulating and solving scientific problems, performing the research, communicating with others and presenting the research results. He/she will be also able to solve several technical issues effectively, both in individual as well in team work. It include the design and implementation of the solutions specific to the area of a given specialty of the studies, also on the system level and including non-technical aspects in conditioning.

The studies of SST has obtained the financial support from the Polish National Centre for Research and Development in the form of the European Social Fund resources allocated for 
the implementation of the educational project "Adjusting the MSc studies Space and Satellite Technologies to the needs of the employment market". The activities undertaken to achieve the aims of the project rely on strict co-operation of the employers representing the space sector with the university. The representatives of firms operating in the space sector are taking part directly in preparing the contents of lessons for students, and also in delivering lectures and working with students during labs, seminars etc. Also, the team project and student dissertation projects are realized in co-operation with firms. As a result, students are expected to be better prepared to the requirements of the space sector employers.

\section{CASE Study Results}

Three editions of the SST studies have been started so far, namely, 2017/2018, 2018/2019 and 2019/2020, the last one is currently in progress.

The case study has been carried out in April 2019 on a group of 20 people. It covered students from both the first and second year of the SST course. The survey consisted of closed and opened questions with single and multiple choices, in order to provide the best possible feedback and freedom of speech in case of each individual. The main aim of this case study was to determine their background, source of information, motivation, as well as expectations related with the SST course as well as space science as a novel and broad field of study. The extract from the results is presented below.

Fig. 1 describes the background of current SST students.

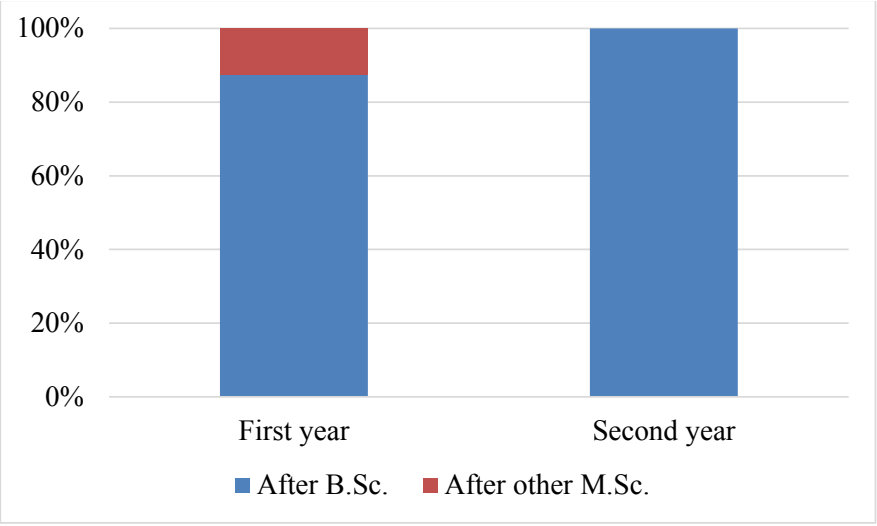

Fig. 1. Student background

As shown, in both cases the vast majority had chosen the SST course after B.Sc. studies. In case of the current first-year students, only approx. $10 \%$ had chosen SST as an additional M.Sc. specialty.

Their main sources of information, considering the third edition of SST course, are shown in Fig. 2. As shown, in case of approx. $50 \%$, their main source of information was the GUT recruitment website. Internet advertisement campaigns, considering various adds as well as data distributed using social media, came in second. Other sources, including printed media, came in third place.

The main reasons and motivations for choosing this field of study, are shown in Fig. 3.

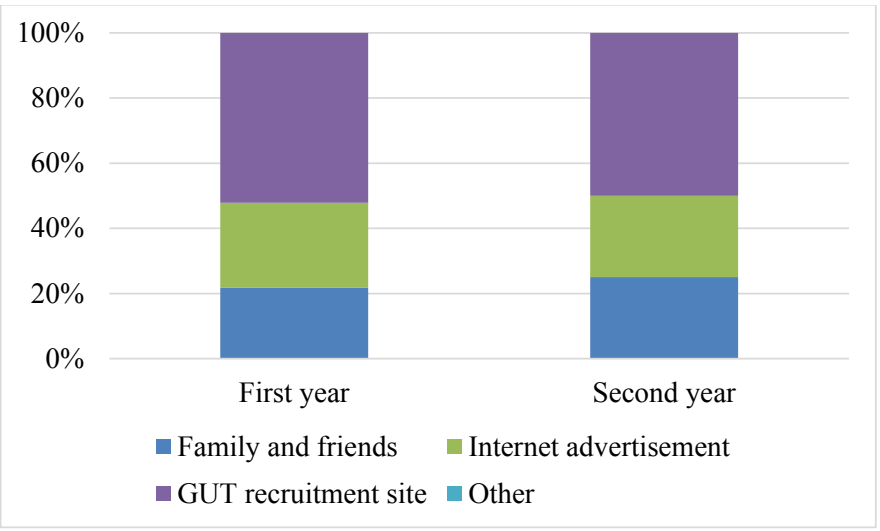

Fig. 2. Source of information concerning SST studies

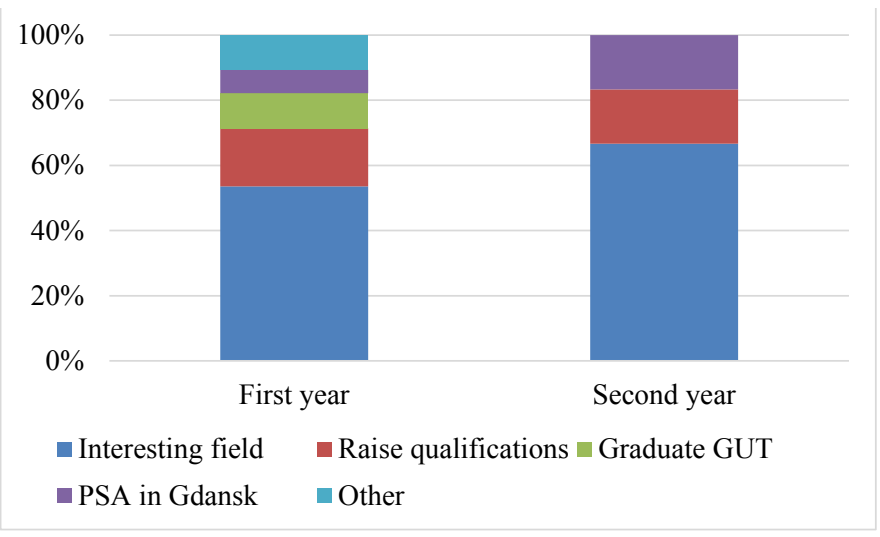

Fig. 3. Motivations for choosing SST studies

As shown, the vast majority concerned Space Science Technologies as an interesting and bold field of study. Some of them wanted to simply raise their qualifications or become a graduate of the GUT. Not surprisingly, a number of students pointed out the fact of founding the Polish Space Agency, headquartered in Gdansk.

The majority of SST students prefer laboratory and project classes over classical lectures $(94 \%$ vs. $6 \%$ of the first year students and $75 \%$ vs. $25 \%$ of the second year students).

As pointed out, they desire to gain practical knowledge as well as typical engineering skills that can help them not only in private life, but mostly in their professional career. Currently, our SST course offers more laboratories and project classes, and most students would like to keep it this way. According to numerous answers, this course enables them to pursue their passion and learn unique knowledge and skills, that can help them find interesting jobs on the market. According to obtained results, as shown in Fig. 4, half of our students combines M.Sc. studies with professional work.

Whereas, most of them has part-time jobs, while some individuals favor self-employment. It should be noted, that some students had experience in IT and related fields from previous B.Sc. studies. Whereas others, that came from a different background, started their professional career after the first year of SST studies. 


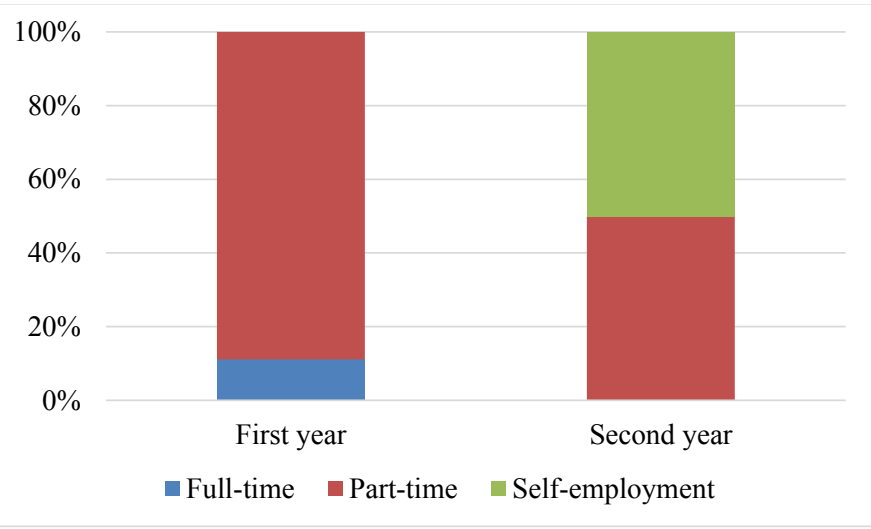

Fig. 4. Combining studies with professional work.

Many individuals would like to pursue their passion, and continue studies as Ph.D. students. As shown in Fig. 5, their main motivation would be grants, closely linked with conference and publication activities.

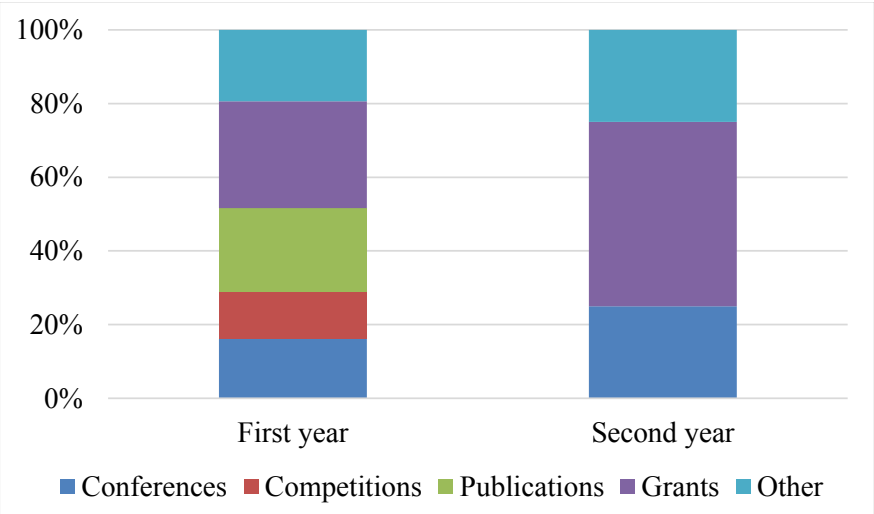

Fig. 5. Combining studies with professional work.

Naturally, the possibility of testing ones skills in academic and scientific competitions would be an important factor.

\section{STUDENT ACTIVITIES}

In addition, it may be stressed that the SST students have got numerous achievements. The HEDGEHOG team [2] has qualified to REXUS/BEXUS programme, organized by German Space Agency (DLR) and Swedish Space Agency (SNSB), coordinated by ESA. The successful flight of the rocket with the experiment took place in March 2019. Currently, another group of students take part in the Spin Your Thesis! program. Apart from that, a number of students participated in space related conferences, workshops and other activities, including hands-on courses by ESA Academy: Concurrent Engineering Workshop, or Cubesat Workshop.

These students have founded a student organization SpaceCube. Its goals have been set to foster cooperation with academia and space sector companies as well as broadening the gap between course curriculum and future careers skills required by employers. Their main project is a nanosatellite type $1 \mathrm{U}$ Cubesat, aiming to test new type of solar cells developed at Gdańsk University of Technology. SpaceCube's activities include also popularization of STEM sciences among middle and high school pupils. Furthermore, their concept of "Space Navigation System", allowing for precise navigation on LEO and beyond was awarded 2nd prize at Poland's edition of Galileo Masters Competition 2017.

Engagement of three academia in space engineering resulted in some scientific results as well. A first $\mathrm{PhD}$ thesis in dynamics of spacecraft payload vibration is ongoing. Furthermore, a cooperation with Centre for Space Research of Polish Academy of Sciences has been developed to work on their space robot testing facility [3]. Additionally, members of faculty together with local space sector companies have proposed numerous research and development projects, some already funded by National Centre for Science and Development or European Commission. For instance, the subject of one project was the design of very light and durable lattice structure materials and the possibility of their use in the structure of satellites.

Another group of students was engaged in the project concerning floodplain inundation mapping using SAR data processing [4]. The study has been conducted in Biebrza floodplain, Poland, with the use of automatic thresholding method for processing Sentinel 1 data.

\section{CONCLUSIONS}

At the end, a preliminary sum-up may be made, although the SST studies were opened relatively short time ago, and the relatively small group of students has been covered by the mentioned study. Mainly, the SST students are well motivated to their educational, as well as research activities, usually indicating their real interest in space science and technology as the main reason for choosing this field for studying. Due to the interdisciplinary character of SST, the students, representing different fields from the point of view of their background, are open for learning new knowledge and skills as well as for participating in many activities like workshops, competitions etc. Also, the students are characterized by the high level of self-reliance and they are well prepared for combining the M.Sc. studies with parallel professional work.

As shown, the field of Space Sciences, in which our Space Science Technologies course is settled, is a novel and interesting research area. It attracts many young people, with different backgrounds, motivations and expectations. Most of all, it opens new frontiers and enables them to pursue their passion in one of the most rapidly developing field.

\section{REFERENCES}

[1] M. Chodnicki, E. Wittbrodt, A. Dąbrowski, Z. Łubniewski, “»Space \& Satellite Technologies « intercollegiate master-degree courses of study in Tri-City (Poland)", $2^{\text {nd }}$ SSEA, Budapest 2018.

[2] A. Dąbrowski, A. Elwertowska, J. Goczkowski, K. Pelzner, S. Krawczuk, "High-quality experiment dedicated to microgravity exploration, heat flow and oscillation measurement from Gdańsk", $2^{\text {nd }}$ Sympsium on Space Educational Activities, Budapest 2018.

[3] K. Seweryn, K. Grassmann, K. Rutkowski, T. Rybus, R. Wawrzaszek, "Design and development of two manipulators as a key element of a space robot testing facility", Archive of Mechanical Engineering, vol. 62 , no. 3, 2015 .

[4] T. Berezowski, T. Bieliński, J. Osowicki, "Floodplain inundation mapping using SAR scattering coefficient thresholding and observed discharge data", IGARSS 2019 Proceedings, in press. 